DR 505:Disaster Challenges for Vulnerable Population-

Physical and Age related

(Monsoon Semester, 2021)

Third Semester, 2021

Assignment - 01

\begin{tabular}{|l|l|}
\hline Submitted To: & $\begin{array}{l}\text { Submitted By: } \\
\text { Sumit Narayan }\end{array}$ \\
Assistant Professor & $\begin{array}{l}\text { Master of Arts- III Sem (Disaster } \\
\text { Studies) }\end{array}$ \\
Special Centre for Disaster & $\begin{array}{l}\text { Special Centre for Disaster Research } \\
\text { Jawaharlal Nehru University }\end{array}$ \\
Research & \\
\hline
\end{tabular}




\title{
Disabled Children in Disaster Management
}

\author{
Sumit Narayan ${ }^{1}$ \\ ${ }^{I}$ Special Centre for Disaster Research \\ Jawaharlal Nehru University, Delhi, India \\ ${ }^{1}$ sumit28_cdr@jnu.ac.in \\ ${ }^{1}$ sumitnarayan.jnu@gmail.com
}

\begin{abstract}
Disabled children have a wide range of impairments, talents, and capacities, which collide with a wide range of circumstances and societal attitudes. The following article discusses disaster management in the context of disabled children. Disaster, disability and its management is discussed in the context of international practices in general and suited to India in particular. The research follows a review of the United States National Commission on Children and Disaster and its extrapolations to India. In addition to this Disaster Medicine as one approach to Disaster Management concerning disabled children has been explored. The research concludes that the understanding of particular issues of Children with disabilities as one stakeholder and their capacity to engage, as well as a shift in mindset and power relations in which children with disabilities contribute to DRR projects, are fundamental to disability-inclusive DRR.
\end{abstract}

Keywords — Disaster, Disability, Disaster Management, NCCD, UNCRPD, Disability \& Disaster, Disaster Medicine

\section{Introduction}

The ongoing COVID-19 pandemic has highlighted the "disability of disabled children" amidst a disaster. It posed a "triple burden" for disabled children in the form of: the elevated risk of poor disease outcomes, restricted access to regular health care and rehabilitation, and the negative social implications of pandemic mitigation activities. Children with disabilities are abandoned or left behind before, during, or after a disaster, this has been demonstrated historically during disasters.

\section{Disability, Disaster and Disaster Management}

\section{A. Disability}

The term "disability" is defined in a variety of ways, with different individuals and organisations having their own definitions. A disability, according to the Centre for Disease Control and Prevention (CDC), is any physical or mental impairment that makes it more difficult for a person to conduct specific tasks (activity limitation) and interact with the environment around them participation restrictions.

According to the United Nations (UN) United Nations Convention on the Rights of Persons with Disabilities, disability is a developing term that arises from the interaction between persons with impairments, as well as psychological and environmental hurdles that keep individuals from completely and successfully engaging in society on an equal level with others.

In the context of India, the 2016 Rights of Persons with Disabilities Act defines a "person with disability" as a person who has a long-term physical, mental, intellectual, or sensory impairment that, when combined with barriers, prevents him from participating fully and effectively in society on an equal footing with others. Same act also defines a "Person with benchmark disability" as a person who has not less than $40 \%$ of a specified disability that has not been defined in measurable terms, as certified by the 
certifying authority, and includes a person who has a disability that has been described in measurable terms.

Disaster research definitions of disability are best subsumed within the WHO's International Classification of Functioning, Disability, and Health, given these diverse taxonomies. The ICF defines disability as the outcome of an interaction between an individual's health condition and their personal and environmental circumstances. Disability is described as a loss of function or structure in the body, a limitation in a certain activity, or a restriction in social involvement.

\section{B. Disaster}

The term disaster is derived from the 16th century French word "disastre," according to the Oxford English Dictionary (OED). The OED defines a disaster as "an unexpected event, such as a very bad accident, a flood or a fire, that kills a lot of people or causes a lot of damage".

According to sec2 (d) 0f Disaster Management Act 2005 " disaster" means a catastrophe, mishap, calamity or grave occurrence in any area arising from natural or manmade causes or by accident or negligence which results in substantial loss of life or human suffering or damage to deterioration of property or damage to or degradation of, environment and is of such a nature or magnitude as to be beyond the copying capacity of community of the affected area.

Accordingly, a disaster can be defined comprehensively as "an occurrence arising with little or no warning, causing or threatening serious disruption of life, and possibly death or injury to large numbers of people, and requiring, as a result, a mobilisation of effort in excess of that normally provided by the statutory emergency services,"

\section{Disaster Management}

According to sec2 (e) 0f Disaster Management Act 2005 "disaster management" means a continuous and integrated process of planning, organising co coordinating and implementing measures which are necessary or expedient for

(i) Prevention of danger and any threat of disaster

(ii) Any disaster's risk of occurrence, intensity, or effects is mitigated or reduced.

(iii) Capacity building

(iv) Preparedness to deal with any disaster

(v) Response to any serious crisis situation or tragedy as soon as possible.

(vi) Determining the intensity or degree of a disaster's consequences

(vii) Evacuation, rescue and relief

(viii) Rehabilitation and reconstruction.

Natural disasters disrupt societies by claiming lives, creating victims, and destroying infrastructure and homes. By striking disasters, funds and budgets designated for development purposes are diverted to disaster response and restoring normalcy to the quality of life. Natural disasters have a negative impact on the environment because they devastate natural resources. As a result, given that society, economy, and environment are the three main components of sustainable development, disasters have a negative impact on them, resulting in a negative impact and delay on sustainable development. With this in mind, appropriate disaster management can help to reduce the negative effects on development activities.

\section{III.Linkages Between Disability and Disaster}

When it comes to the linkages between disabilities and disasters, disasters can induce or exacerbate impairments, as well as cause human injuries and fatalities. An event that impacts a community, the consequences of which go beyond the immediate financial material are emotional 
resources of the community," writes P.C Sinha in his Introduction to Disaster Management.

Disasters can also result in disability. Crush injuries might entail amputations in earthquakes, and a catastrophic fall can result in chronic spine injury. Crush syndrome can also result in renal or cardiac failure. However, the number of such occurrences is insignificant when compared to the total number of injuries. Because bomb strikes can result in a wide range of injuries, the danger of permanent impairment is substantially higher. They include explosion effects within the body (barotrauma), penetrating injuries from shrapnel, fragmentation of bones, severe burns, and damage to the lungs.

The impact of disasters on children with disabilities varies depending on the circumstances, such as human loss, physical injuries, building collapse, mental illness, uneven treatment, and so on. The impact of a sequence of disaster events on children with disabilities varies depending on the circumstances, including repercussions such as human loss, physical injuries, building collapse, mental disorder, uneven treatment, and others.

\section{United States National Commission on ChildRen and Disasters (NCCD)}

The President of the United States and Congress tasked the National Commission on Children and Disasters with conducting the first-ever comprehensive review of Federal disaster-related laws, regulations, programmes, and policies to assess their responsiveness to children's needs and make recommendations for closing critical gaps.

Some of the important recommendations produced by NCCD are given in Box 1 .

India has one of the world's highest proportions of people in the younger age categories. At the time of the 2001 Census, 35.3 percent of the country's population was aged 0 to 14 . About $42 \%$ of the population is under the age of eighteen according to census of India 2011.

$$
\text { BOX 1: RECOMMENDATIONS OF NCCD }
$$

Recommendation 1.1: Distinguish and comprehensively integrate
the needs of children across all inter- and intra-governmental
disaster management activities and operations.
Recommendation 1.2: The President should accelerate the
development and implementation of the National Disaster Recovery
Framework with an explicit emphasis on addressing the immediate
and long-term physical and mental health, educational, housing,
and human services recovery needs of children.
Recommendation 1.3: DHS/FEMA should ensure that information
required for timely and effective delivery of recovery services to
children and families is collected and shared with appropriate
entities.

Recommendation 2.1: HHS should lead efforts to integrate mental and behavioral health for children into public health, medical, and other relevant disaster management activities.

Recommendation 3.5: Prioritize the recovery of pediatric health and mental health care delivery systems in disaster-affected areas.

Recommendation 6.2: Congress and Federal agencies should improve capacity to provide child care services in the immediate aftermath of and recovery from a disaster.

Recommendation 7.1: Congress and Federal agencies should improve the preparedness of schools and school districts by providing additional support to States.

Recommendation 8.2: Ensure that State and local juvenile justice agencies and all residential treatment, correctional, and detention facilities that house children adequately prepare for disasters.

Recommendation 9.1: Government agencies and

non-governmental organizations should provide a safe and secure mass care shelter environment for children, including access to essential services and supplies

Recommendation 10.1: Prioritize the needs of families with children, especially families with children who have disabilities or chronic health, mental health, or educational needs, within disaster housing assistance programs.

Recommendation 11.1: Congress and Federal agencies should provide sufficient funding to develop and deploy a national information sharing capability to quickly and effectively reunite displaced children with their families, guardians, and caregivers when separated by a disaster.

Given the large number of children in India, the US Commission's recommendations that children's special needs should be better integrated into planning and made a clear and distinct priority in all disaster relief efforts hold a significant weight.

Because of their young age and lack of disaster experience, they are psychologically sensitive. 
Children have a high level of post-traumatic stress disorder, which can be caused by a variety of factors including shock from the chaos and panic caused in the neighbourhood during disasters, seeing their loved ones die or be injured, damage to their homes, loss of belongings, lack of food, self-injury, and dissociation from their siblings and parents.

Disaster risks can be reduced by providing a safety net for children, ensuring that they are protected and able to deal better in the event of a disaster. There is a need to comprehend the dangers that youngsters confront in the neighbourhood. Children must be prioritised in village disaster management plans when it comes to rescue or evacuation in the event of a disaster. Because students spend so much time in schools, school safety becomes a major concern. Because children are quick learners, they must participate in all exercises for school safety. As a result, it is critical to identify threats involving children on school grounds and to design a school crisis management strategy that includes regular mock drills and first-aid training.

Disaster risks can be reduced by providing a safety net for children, ensuring that they are protected and able to deal better in the event of a disaster. There is a need to comprehend the dangers that youngsters confront in the neighbourhood. Children must be prioritised in village disaster management plans when it comes to rescue or evacuation in the event of a disaster. Because students spend so much time in schools, school safety becomes a major concern. Because children are quick learners, they must participate in all exercises for school safety. As a result, it is critical to identify threats involving children on school grounds and to design a school crisis management strategy that includes regular mock drills and first-aid training.

\section{Disaster Medicine in the Aid of Children in Disaster}

Regardless of national boundaries, the problem of disaster medicine as a separate speciality of medicine, public health or disaster management has been particularly important for children with disabilities. Disaster medicine includes not just emergency medical rescue but also emergency relief efforts, which are fundamentally distinct from hospital emergency care.

The field of disaster medicine encompasses the study of a variety of medical specialties. Depending on the type of incident that happened, disasters can result in a variety of injury and illness patterns. Earthquakes can result in entrapment and crush syndrome; tornadoes can result in penetrating damage from flying debris; and infectious disease outbreaks can be caused by a variety of bacteria, viruses, and fungi. The disaster medicine specialist must be trained on the different injury and sickness patterns encountered in catastrophe victims due to the possibility for heterogeneity in casualty circumstances.

\section{Concluding Remarks}

Disabled children have a wide range of impairments, talents, and capacities, which collide with a wide range of circumstances and societal attitudes. As a result, they are vulnerable and marginalised to differing degrees, necessitating a variety of measures to address their requirements.

It is advised that a thorough framework be used that includes tools for planning, implementation, and evaluation as well as graded levels of DRR integration based on resources. Children with disabilities and their capacity to engage, as well as a 
shift in mindset and power relations in which children with disabilities contribute to DRR projects, are fundamental to disability-inclusive DRR. DRR for children should therefore rely on ongoing knowledge sharing and agreement building around gap identification in order to jointly design effective disability-inclusive programmes.

Numerous obstacles have hampered disaster management's capacity to achieve its ultimate aim of decreasing not only the physical but also the social impact of disasters, which disability inclusion may help to achieve. The fact that all stakeholders have distinct duties to play in including disabled children in the field is extremely beneficial to not just those children but also other stakeholders. Before, during, and after disasters, numerous hurdles (e.g., physical barriers, communication barriers, attitudinal barriers, and so on) that children with disabilities have often faced will be reduced. Inclusion will be a cornerstone for the entire profession because it will allow us to lessen human loss and psychological stress caused by disasters.

\section{REFERENCES}

1. Act No. 49 of 2016. The Rights of Persons with Disabilities Act, 2016. , (2016).

2. Agency for Healthcare Research and Quality (Ahrq). (2010). National Commission on Children and Disasters. 2010 Report to the President and Congress.

3. CDC. (2020, September 15). Disability and Health Overview. Retrieved January 3, 2022, from Centers for Disease Control and Prevention website: https://www.cdc.gov/ncbddd/disabilityandhe alth/disability.html

4. Ciottone, G. R. (2016). Introduction to Disaster Medicine. In Ciottone's Disaster Medicine (pp. 2-5). Elsevier. Retrieved from

http://dx.doi.org/10.1016/b978-0-323-28665 $-7.00001-7$

5. Disaster Management Act, 2005. Act No. 53 of 2005. , (2005).

6. disaster noun - Definition, pictures, pronunciation and usage notes. (n.d.). Retrieved January 3, 2022, from Oxford Advanced Learner's Dictionary at OxfordLearnersDictionaries.com website: https://www.oxfordlearnersdictionaries.com/ definition/english/disaster

7. Jang, J.-H., \& Ha, K.-M. (2021). Inclusion of Children with Disabilities in Disaster Management. Children, 8(7), 581. https://doi.org/10.3390/children8070581

8. Office of the Registrar General \& Census Commissioner, India. (2011). Census of India: Age Structure And Marital Status. Retrieved January 2022, from https://censusindia.gov.in/census_and_you/a ge_structure_and_marital_status.aspx

9. Shakespeare, T., Ndagire, F., \& Seketi, Q. E. (2021). Triple jeopardy: Disabled people and the COVID-19 pandemic. The Lancet, 397(10282),

1331-1333. https://doi.org/10.1016/s0140-6736(21)0062 $5-5$

10. Sinha, P. C. (1998). Introduction To Disaster Management. Anmol Publications PVT.

11. United Nations. Convention on the Rights of Persons with Disabilities.

12. WHO. (2001). International Classification of Functioning, Disability and Health (ICF). Retrieved January 3, 2022, from https:/www.who.int/standards/classification s/international-classification-of-functioningdisability-and-health 
